\title{
The role of the
}

\section{foundation dentist in}

\section{the dental team and} the legal liabilities for their employer during COVID-19

\section{Len D'Cruz and Vicki Swanton} Head of BDA Indemnity and Partner at DWF Law LLP

Head of BDA Indemnity and Partner at DWF Law LLP the support they needed and of course an overarching concern about what the future actually holds. ${ }^{1}$ Due to COVID-19, the latest cohort of FDs will have discovered a very different practice environment than was the situation 12 months earlier:

$\rightarrow$ The number of patients attending general practice has dropped because of the operating procedures imposed to reduce COVID-19 transmission. It will be slower for the FD to achieve their treatment targets. The quota time limit (and supervision) may also have to be extended

$\rightarrow$ External training sessions will be presented individually online instead of face to face group seminars

$\rightarrow$ When the FD is undertaking unfamiliar aerosol generating procedures (AGPs) it will be necessary for the trainer to be present from the start of the procedure wearing PPE so that the FGP could be mentored when necessary, rather than expending additional time changing into PPE part-way through the procedure. This requires careful organisation of both appointment books.

All this means a very different approach when preparing these recent graduates for the world of dentistry post-COVID-19. It also highlights the significance of the boundaries that exist between the ES and the FD in terms of their clinical responsibilities for the patient's care.

\section{On the job training}

We know that to practise safely and attain proficiency in dentistry requires 'deliberate' practice to hone technical skills through hours of experience on the job during the foundation year.

Acquisition of the necessary skills is achieved by repetition, critical reflection, mentoring and situational awareness. There are formal processes in the curriculum to assess skills in the electronic portfolio such as ADEPTS, CBD and early stage peer review of basic skills with which the ESs will be familiar.

Each ES will spend time discussing cases with the FD, offering advice on patient management, alternative treatment plans and often going into great detail about the treatment of individual teeth - assessing their restorability, for example.

This invaluable support helps acclimatise FDs into the practice environment and prepares them for many of the challenges they will be facing, including patient complaints. The sad reality is that whilst the prospect of a complaint should not stunt the progress of a FD or make them fearful of risk with many doing it alone and without 
or doing new procedures, they need to be made aware that this is a mundane fact of life in general practice.

\section{Legal liabilities}

This leads onto the next testing point to which FDs and ESs need to be alert, namely the risk that a few of the patients, who criticise their treatment and make a complaint, will not be satisfied with the response they receive and will escalate their concern into a clinical negligence claim.

If a claim does materialise the main point to remember is that all FDs are registered in their own right as independent dentists and so they must have their own personal indemnity to cover them for any claims brought against them. Because a legal claim can be challenging for everyone involved in the dissatisfied patient's treatment, it is typically assumed that the responsibility falls to the FD and their indemnifier to manage.

In fact, the reality is often complex and a tactic adopted by many 'no-win, no-fee' law firms acting for patients is to spread the net wider than just the FD. This means that when a patient treated by the FD subsequently instructs solicitors to investigate a clinical negligence claim (or possibly bring a claim themselves without a legal representative) the resulting allegations are not only directed to the FD but could also involve:

$\rightarrow$ The owner of the practice in contract

$\rightarrow$ The owner of the practice and ES personally should they have been involved in the criticised care directly

$\rightarrow$ The owner of the practice and/or ES as being vicariously liable for the negligent acts and omissions of the FD

$\rightarrow$ The practice entity owing the patient a nondelegable duty of care.

The 'ingenuity' adopted by some claimants is frustrating when it is absolutely clear that the FD is in fact employed by the practice, on the payroll for the duration of the year, and has indemnity to meet any negligence claims that arise during the course of their employment

Practice owners and ESs need to be prepared for such a 'scatter gun' approach, particularly as a claim made against the FD could be made simultaneously against the practice owner and perhaps even the ES who will have responsibility for training, supervising and monitoring the recent graduate. In certain instances the owner/ ES might have assisted in the treatment planning, execution and delivery of the treatment, now being criticised by the patient, either directly, whilst assisting the FD in a difficult extraction for example, or simply by being present during an ADEPT. To further complicate things, in some areas, the Health Education Authority/Deanery has appointed a single lead employer, for all the FDs in their area, and for whom separate legal advice may be required.

What is vicarious liability and a nondelegable duty of care?

A detailed exposition of these two legal concepts is beyond the scope of this article but suffice it to say they can often give lawyers a headache!

Vicarious liability is a tool that potentially imposes liability upon a person/organisation who has a 'qualifying relationship and connection of conduct' with the person who actually provided the criticised care.

Non-Delegable Duty of Care is a mechanism where, once again, liability is potentially imposed upon an organisation that was not directly involved in delivering the criticised care on the basis that they have a statutory duty to provide the care that has been provided in a substandard way by another.

\section{Vicarious liability - are you vulnerable?}

The classic case in which vicarious liability could be imposed on an organisation/ individual not directly involved in providing the criticised care is upon an employer for the injury and damage caused by an employee.

But, what about situations where the wrongdoer was an independent contractor, or where the wrongdoing occurred at a time when the individual was acting beyond the scope of their employment/contracted duties?

In such circumstances, it becomes necessary to consider exactly what the contractual relationship was (even if a contract seeks to label someone as an independent contractor the court can still probe the realities and if appropriate find a relationship that is akin to an employment situation). If satisfied that there is a relationship that effectively amounts to one of 'employment' the next question, before vicarious liability can be established, is whether the criticised care/conduct arose because of a particular aspect of that relationship?

Examples that the court has had to wrestle with to date are referenced below and include: $\rightarrow$ If a prisoner who negligently injured a prison employee whilst assisting with kitchen duties was an employee of the Ministry of Justice ${ }^{2}$

$\rightarrow$ When a dental practice owner could be held responsible for the negligent treatment provided by an associate with no valid indemnity arrangements in place ${ }^{3}$

$\rightarrow$ Whether an occupational health physician retained as an independent contractor (criticised for abuse during examinations of potential employees) could be in a relationship akin to employment. ${ }^{4}$

\section{Non-Delegable Duty - could you be} exposed?

Another legal concept that taxes those involved in clinical negligence litigation first came to prominence in 2012 when an Education Authority was held responsible for the actions of two independent contractors (swimming teacher and lifeguard) following a tragic accident involving a pupil participating in a school swimming lesson. ${ }^{5}$ More recently it has arisen in a dental context where a practice was found to owe such a duty to a patient. ${ }^{6}$

As with vicarious liability, the factual situation has to be reviewed in detail but, where an NHS patient is being treated, the imposition of a statutory duty to ensure care is taken is a potential risk for the practice/ practice owner.

\section{Learning points for practice owners} and education supervisors

Supporting FDs to gain on-the-job experience and preparing them for the rest of their dental careers is an invaluable role provided by ESs and indeed everyone in the dental team. Ideally, the training year should be a positive experience for everyone in the practice but there is a definite need for all parties to be alive to the risk of a patient complaint and negligence claims and plan accordingly.

As part of that planning, it is important that FDs, ESs and practice owners should have clearly written contracts and professional indemnity in place. If you are in any doubt as to the scope of your indemnity arrangements, then check with your provider and remember, should a potential claim arise, be sure to notify them immediately.

\section{References}

1. Westgarth $D$. What does the future hold for the workforce of tomorrow? BDJ In Pract 2020; 33: 12-17

2. Coxv MOJ 2016.

3. Whetstone $v$ Medical Protection Society 2014.

4. Barclays v Various Claimants 2020

5. Woodland $v$ Swimming Teaching Association and Others 2013.

6. Ramdhean v (1) Alfredo Agedo (2) The Forum Dental Practice Limited.

https://doi.org/10.1038/s41404-020-0548-8 